Journal of Social and Development Sciences

Vol. 4, No. 10, pp. 461-466, Oct 2013 (ISSN 2221-1152)

\title{
The Role of Clinical Governance in the Health Management Systems of Thailand
}

\author{
John Walsh \\ Director, SIU Research Centre, SIU, Bangkok, Thailand \\ jcwalsh100@hotmail.com
}

\begin{abstract}
The health industry in Thailand is changing as a result of several important changes in society and projected future changes. These include the need for political and social reasons to extend low cost and easy access health care further to every sector of society in all regions of the country, the continuing aspiration to become an international hub for health tourism, the need to adjust to the potential flow of professionals across Southeast Asia resulting from the projected 2015 ASEAN Economic Community and the restructuring of the labour force as part of the effort to exit from the Middle Income Trap. These changes are nation-wide and require cooperation from a range of ministries, as well as requiring the support of society as a whole; that support will result from fostering of social solidarity through, in part, better explanation of why policies are changing and what the objectives will be in the short, medium and long-terms. It is, of course, essential that proper management of quality and health care within involved organizations - i.e. clinical governance - is also fostered and maintained at the highest possible level in both the public and private sectors.
\end{abstract}

Keywords: Clinical governance, healthcare, Thailand

\section{Introduction}

Thailand is a developing country that has reached middle income status and is located in a tropical monsoon climate zone. As a result, its health management system reflects these basic circumstances. As a developing country, it has limited scope and reach of organized health services which are better provided in central or urban locations than in outlying regions. Doctors, who are selected from the highest achieving entrants into the university qualification system, are accorded high status and tend to operate on a hierarchical basis, with the hospitals the centre of their power base. Those who work in the provinces, especially remote rural provinces, tend to be less well-regarded. As it is a country that has achieved middle income status, Thailand's population of around 70 million has started to exhibit the health problems of a globalised society: these include obesity, mature onset diabetes (Chopra, Galbraith \& Darnton-Hill, 2002) and conditions caused by pollution, road traffic accidents and workplace safety incidents. These are added to climate-specific issues such as tropical diseases, dengue fever, typhus and the unfortunate results of interaction with dangerous wildlife (Suankratay, Wilde \& Berger, 2001). Thai scientists have developed considerable expertise in some of the particular issues affecting territories in tropical climates.However, their expertise will be severely challenged by the emerging threats posed by global climate change and its impacts (McMichael, Patz \& Kovats, 1998).

Political, historical, social and cultural factors have all been influential in structuring, in part, responses that have been made to try to deal with health problems on a rational and more or less equitable basis. This takes place, nevertheless, in the context of considerable structural inequalities that are being intensified by the continued intensification of capitalism across Thailand and this is manifested in unequal access to health care and differential pricing regimes (Pannarunothai \& Mills, 1997).This paper aims to outline the ways in which Thai organizations have responded to these initial conditions and explain some of the reasons why this has taken place in the way it has. In doing so, it raises the concept of clinical governance as a central issue in ensuring the quality of healthcare in recognized premises. Clinical governance is an emerging and changing concept that is becoming influential in healthcare management internationally (Som, 2004) and is being explicitly integrated into existing health management regimes in Thailand. 


\section{Thailand the Nation}

Uneven development has been a notable characteristic of Thailand and this has intensified in the era of rapid economic development that began in earnest in the 1950s. Thailand benefited from American support during the Cold War period through the provision of markets and infrastructure so as to assist the state-led suppression of a possible Communist insurgency. The country entered the factory and field age with its own variant of the East Asian Economic Model - import-substituting and export-oriented original equipment manufacturing based on competitiveness from low labour costs resulting from pre-Lewisian point agricultural labour and the often violent suppression of workers' rights, freedom of association, freedom of speech and collective bargaining (Walsh, 2013). This process led to the creation of places of production which were intensive and densely concentrated and made for new health issues - young workers were crowded together and had opportunities to indulge in risk-taking behaviour that was involved in the spread of HIV/AIDS, for example, as also did the effect of intensifying the importance of the capital city, Bangkok, which had for some time been known as a Primate City - that is, a city which contains all the most important political, economic, social, religious and monarchical institutions of the entire country (McGee, 1967). Health institutions are included in this, as Table 1 below indicates.

Table 1: Health Indicators for Different Regions in Thailand; source: compiled from various sources by the author

\begin{tabular}{lllll}
\hline & Physicians & $\begin{array}{l}\text { Population/ } \\
\text { Physician }\end{array}$ & Patient Beds & $\begin{array}{l}\text { Population/ } \\
\text { Hospital Beds }\end{array}$ \\
\hline Whole Kingdom & 19,089 & 3,328 & 117,568 & 540 \\
Bangkok & 4,591 & 1,242 & 15,074 & 378 \\
Vicinity of Bangkok & 1,616 & 2,806 & 12,882 & 352 \\
Central & 896 & 3,323 & 6,995 & 426 \\
Eastern & 1,552 & 2,937 & 10,991 & 415 \\
Western & 921 & 3,987 & 6,986 & 526 \\
Northeastern & 4,423 & 4,860 & 29,673 & 724 \\
Northern & 2,789 & 4,220 & 17,419 & 676 \\
Southern & 2,301 & 3,830 & 17,548 & 502 \\
\hline
\end{tabular}

In recent years, political conflict has centred on the control of the democratic institutions of the land and, also, on the struggle to bring previously unaccountable and non-democratically controlled institutions into the light and make them accountable to the democratically-elected government. It has yet to be settled whether the democratic or the various anti-democratic factions that are confronting each other on the streets of Bangkok will see their side triumphant or whether there will be further confusion and ambiguity in the future. The result of the struggle will have significant implications for the nature of governance in Thailand. Currently, various institutions and governmental and semi-governmental agencies wield considerable influence and power in the Kingdom and their tendency has been, especially since the financial crisis of 1997 (Hewison, 2005), to adopt a technocratic approach that is combined with perceptions of virtue: that is, it is an opaque system that is conservative in nature and believes that it is justified in holding its position and power. This is evident in the patriarchal and elite-dominated health system in Thailand, particularly in the public sector.

\section{Governance Overview}

Thailand has a modern, cabinet-based government as part of a representative democracy and a bureaucracy that has gone through several waves of reorganization and professionalization since the turn of the century (Painter, 2006). However, there are still some areas of the country and its administration which appear to be a little unusual for an international perspective or else indicate a certain lack of technical capacity. Being different from international norms is not necessarily a bad thing, of course and might much more accurately reflect the cultural and societal factors relevant to a particular country. For example, the Ministry of Public 
Health incorporates the concept of beliefs and spirituality as part of its understanding of wellness (MoPh, 2013). These feed in to the notion of the individual as a functional part of the wellness idea, together with the external factors of the environment and the mediating institutions of the health system. There is also a slightly ambiguous relationship with the domain of Chinese or oriental medicine. On the one hand, it is regarded as a respectable body of knowledge of long-standing and with many eminent practitioners; on the other hand, it can be confused with some of the non-scientific practices treated with suspicion by westerntrained scientists. This is perhaps symptomatic of the ambivalent attitude felt by many Thai people with respect to the rest of the world (see, for example, Harrison, 2010). It is also the case that the high cost of western, rational-scientific medicines has enabled traditional or oriental remedies have been reinvented or recreated as low cost alternatives to imported solutions (Chokevivat, Chuthaputti \& Khumtrakul, 2005).

In terms of technical capacity, there is the issue of the interaction between doctors and the remains of deceased patients and the issue of cause of death and insurance agencies. In the first case, there is a choice of means of having the deceased moved to the place of rest and it is doctors who are generally able to steer the relatives of the deceased towards one or the other service provider - there is a similar situation in respect to emergency recovery services who collect victims of road traffic accidents and who can, in some cases, exert an influence over where patients are taken and, in a commercial sense, determine who gets the business (Walsh, 2011). In the second case, relatives of the deceased might wish to negotiate with doctors concerning the officially recorded course of death when it may be that the doctor's opinion would affect whether the insurance company makes the compensation payment or not. Consequently, there is some doubt around the margins of some official statistics. Even so, the leading causes of death are consistent with what might be expected from a country undergoing rapid industrialization and modernization, with stroke, ischaemic heart disease, road traffic accidents and HIV/AIDS all prominent (Porapakkam et al., 2010). One noticeable change from 1999-2005 and subsequently has been the significant decline in mortality from HIV/AIDS, in large part because of state-supported campaigns to educate the public and to reduce transmission rates by promoting condom use in the extensive commercial sex industry and among consenting adults gen erally. This change indicates that sufficient social solidarity exists or can be fostered such that meaningful improvements in public health can take place (Hearst \& Chen, 2004). Further evidence that this can be the case is provided by success with some of the Millennium Development Goal objectives, about which the Health Service Research Institute (HSRI) observed:

"Thailand can be proud to have achieved most of the eight UN Millennium Development Goals (MDGs); in particular the three health-related goals.In 1970, Thailand had an infant mortality rate of 68 per 1,000 live births, while today it is estimated at 13 per 1,000 live births. According to a 2008 study published in the medical journal Lancet, Thailand enjoyed the highest annual rate of reduction in child mortality among 30 low- and middle-income countries between 1990 and 2006. The maternal mortality ratio has also shown a similar decreasing trend. In addition, Thailand has been successful at curbing new HIV infection rates by 83 per cent since 1991, thanks to the arduous efforts made by governments and NGOs (Chowdhury \& Phaholyothin, 2012)." It is worth pointing out these examples of success (which are not outstanding in the international context but significant nevertheless) because contemporary Thai political history has been characterized by a distinct lack of social solidarity and the culture ofimpunity that has enabled unaccountable, unelected elements to trample repeatedly on the interests of the majority.

\section{Negative Aspects of Governance}

Although the HSRI has indicated the positiveaspects of the governance of the healthcare system in Thailand, it has also pointed out that problems do exist. For example, the ten points most likely to be problematic are, it claims:

- The government's plan to revive the policy of the 30-baht co-payment

- The budget for health promotion and disease prevention

- Quality of services

- Harmonization of health insurance schemes (i.e. Social Security Scheme (SSS), Universal Coverage Scheme (UCS) and Civil Servant Medical Benefit Scheme (CSMBS))

- Guidelines for primary health care development of the Ministry of Public Health (MoPH) and the National Health Security Office (NHSO) are still different 
- Preparation of reports for requesting the budget from the NHSO

- Responsible areas of the MoPH and the NHSO

- Management of Sub-district Health Fund

- Health problems of migrant workers and their health care systems

- Clarity of decentralization to local government in the future (ibid.)

It is evident that the majority of these problems that remain within the structure of the civil service, in which there is some overlap of functions and responsibilities, redundancy of some operations and unclear procedures and practices. Some of the problems result from the historical legacy of the development of the bureaucracy in the context of numerous embedded patronage networks (Robertson, 1996) and the invention and reinvention of state-people relations under conditions of rapid economic change and, most of the time, autocratic regimes. Other problems relate to the complexity of some issues which are still defeating state governments with many more resources available than Thailand has. For example, companies around the world are struggling to resolve problems surrounding the rights that migrant workers should have in a host country and what rights they might have to bring their family members with them on a semi-permanent or permanent basis (Wickramasakera, 2008). Similarly, the most advanced countries still debate the extent to which they can provide free or subsidized health treatment to its citizens at a time of global economic crisis, global climate change (Posner, 2007) and rapidly changing demographic conditions, which provide a level of uncertainty which might reasonably be described as unprecedented.

Clinical Governance: Clinical governance as a concept arose from changes in the National Health Service of Britain when it was undergoing a variety of traumatic changes, including the neoliberal Thatcherite revolution (Harvey, 2007) and the introduction of quality control and quality assurance concepts that had been brought to the western world from Japanese management thought and its application of Taylorism (Warner, 1994). Clinical governance sought, therefore, from a variety of motivations, to reorganize the architecture of power within a clinical setting to achieve better outcomes, measured from managerial or patient-customer perspectives. The process has been described as 'the systematic joining up of initiatives to improve quality' and 'providing task based training for health professionals, who learn as they do' (Halligan\& Donaldson, 2001). It is evident that, for clinical governance to be successful in practice, there must be some flexibility on the part of health professionals and even for some renegotiation of the relationships between, for example, nurses and doctors (Baker et al., 1999). In the case of Thailand, many of these relationships have become ossified by the largely class-determined nature of university entrance and the effects that graduation have on performance in a labour market that is rigidly structured in terms of qualifications linked to entry qualifications, differentials between ranks and function (i.e. vertical and horizontal distinctions) and incremental annual increases in salary, status and position. Clinical governance is often seen in the context of the Foucauldian concept of governmentality, which treats (with some simplifications) the interactions between policies, responsibilities and mandates in terms of struggles for power among different constituencies (Flynn, 2002; McKee, 2009). Seen in this context, clinical governance is another strand in the attempt to open and democratize opaque institutions on Thailand and this is at the heart of the current and larger political struggle.

\section{Conclusion}

Much of Thailand's bureaucracy and administrative elites are technocratic in nature and often very-well educated and trained. As a result, much of the policy-work that has been completed in the past has been high quality in nature. On the other hand, changes in political governance, overlaps of responsibility and some inadequacies of evidence to support policy have meant that there has been inconsistency in the application of those policies. As is well-established, there can be some conflict between technocrats and politicians when it comes to competition for scarce resources and setting policy (Putnam, 1977; Milne, 1982). The same situation can be reflected at lower levels of authority and responsibility, for example within the context of hospital or clinic management. Much of what is being done in the name of clinical governance is, therefore, perfectly acceptable and certainly contributes to improvements in patient care. However, there will need to be some continued renegotiation in responsibilities and directions at the level of departmental heads and below. The situation is also unable to cope with the structural deficiencies which reinforce inequalities of access spatially and with respect to finances. With a democratically-elected government claiming a mandate not just to 
transforming the economy but also to broadening access to public services, there seems an inevitability about future struggles between institutions.

\section{References}

Baker, R., Lakhani, M., Fraser R. \& Cheater, F. (1999). A Model for Clinical Governance in Primary Care Groups. British Medical Journal, 318 (March 20 $\left.0^{\text {th }}\right)$.

Chokevivat, V., Chuthaputti, A. \& Khumtrakul, P. (2005). The Use of Traditional Medicine in the Thai Health Care System. Regional Consultation on the Development of Traditional Medicine in the South East Asia Region (Pyongyang, June 22 $2^{\text {nd }}-24^{\text {th }}$ ), available at: http://209.61.208.233/LinkFiles/Meetings_document09.pdf.

Chopra, M., Galbraith, S. \& Darnton-Hill, I. (2002). A Global Response to a Global Problem: The Epidemic of Overnutrition. Bulletin of the World Health Organization, 80(12), available at: http://www.scielosp.org/scielo.php?script=sci_arttext\&pid=S0042-96862002001200009.

Chowdhury, M. \& Phaholyothin, N. (2012).Healthcare in Thailand: A Story to Inspire Confidence.The Nation (April 28 ${ }^{\text {th }}$ ), available at: http://www.nationmultimedia.com/opinion/Healthcare-in-Thailand-astory-to-inspire-confiden-30180854.html.

Flynn, R. (2002). Clinical Governance and Governmentality. Health, Risk and Society, 4(2), 155-73.

Halligan, A. \& Donaldson, L. (2001).Implementing Clinical Governance: Turning Vision into Reality. British Medical Journal, 322, 1413-7.

Harrison, R. (2010). Introduction: The Allure of Ambiguity: The 'West' and the Making of Thai Identities, in Harrison, R. \& Jackson, P.A., eds., The Ambiguous Allure of the West: Traces of the Colonial in Thailand, Ithaca, NY: Cornell University Press.

Harvey, D. (2007). A Brief History of Neoliberalism, Oxford: Oxford University Press.

Hearst, N. \& Chen, S. (2004). Condom Promotion for AIDS Prevention in the Developing World: Is It Working? Studies in Family Planning, 35(1), 39-47.

Hewison, K. (2005). Neo-Liberalism and Domestic Capital: The Political Outcomes of the Crisis in Thailand. The Journal of Development Studies, 41(2), 310-30.

McGee, T. G. (1967). The Southeast Asian City: A Social Geography of the Primitive Cities of Southeast Asia, London: G. Bell \& Sons Ltd.

McKee, K. (2009). Post-Foucauldian Governmentality: What Does It Offer Critical. Social Policy Analysis, 29(3), 465-86.

McMichael, A. J., Patz, J. \& Kovats, R. S. (1998).Impacts of Global Environmental Change on Future Health and Health Care in Tropical Countries. British Medical Bulletin, 54(2), 475-88.

Milne, R. S. (1982). Technocrats and Politics in the ASEAN Countries. Pacific Affairs, 55(3), 403-29.

Ministry of Public Health (MoPH). (2013).Thailand Health Profile Report, available at: http://eng.moph.go.th/index.php/health-situation-trend/130-thailand-health-profile-report.

Painter, M. (2006).Thaksinisation or Managerialism: Reforming the Thai Bureaucracy. Journal of Contemporary Asia, 36(1), 26-47.

Pannarunothai, S. \& Mills, A. (1997). The Poor Pay More: Health-Related Inequality in Thailand. Social Science and Medicine, 44(12), 1781-90.

Porapakkam, Y., Rao, C., Pattaraarchachai, J., Polprasert, W., Vos, T., Adair, T. \& Lopez, A. D. (2010). Estimated Causes of Death in Thailand, 2005: Implications for Health Policy. Population Health Metrics, 8(1), available at: http://www.pophealthmetrics.com/content/8/1/14.

Posner, E. A. (2007). Climate Change and International Human Rights Litigation: A Critical Appraisal. The University of Pennsylvania Law Review, 155(6), 1925-45.

Putnam, R. D. (1977). Elite Transformation in Advanced Industrial Societies: An Empirical Assessment of the Theory of Technocracy. Comparative Political Studies, 10(3), 383-412.

Robertson, P. S. Jr. (1996). The Rise of the Rural network Politician: Will Thailand's New Elite Endure? Asian Survey, 36(9), 924-41.

Som, C. V. (2004). Clinical Governance: A Fresh Look at Its Definition. Clinical Governance: An International Journal, 9(2), 87-90.

Suankratay, C., Wilde, H. \& Berger, S. (2001). Thailand: Country Survey of Infectious Diseases. Journal of Travel Medicine, 8(4), 192-203. 
Walsh, J. (2011). Suriya Coffins: Traditions Become Market Opportunities. Society and Business Review, 6(2), 168-75.

Walsh, J. (2013). Thailand and the East Asian Economic Model. Pacific Business Review: A Quarterly Journal of Management, 5(10), 81-8, available at: http://pbr.co.in/Vol\%205\%20Iss\%2010/11.pdf.

Warner, M. (1994). Japanese Culture, Western Management: Taylorism and Human Resources in Japan. Organization Studies, 15(4), 509-33.

Wickramasakera, P. (2008). Globalization, International Labour Migration and the Rights of Migrant Workers. Third World Quarterly, 29(7), 1247-64. 